\title{
Influence of heart size on mortality and reinfarction in patients treated with timolol after myocardial infarction
}

\author{
TORSTEIN GUNDERSEN
}

From the Medical Department, Cardiology Division, Central Hospital in Rogaland, Stavanger, Norway (for the Norwegian Multicentre Study Group)

SUMMARY The influence of heart size on the effect of long term timolol treatment with regard to mortality and reinfarction after myocardial infarction was examined among 1881 patients randomised to either active or placebo treatment. The patients were followed for 12 to 33 months. At the baseline, heart size was determined by $x$-ray film in two projections: 1199 patients had normal heart size, 262 had borderline heart size, and 420 had enlarged hearts.

The incidence of total cardiac death was three times greater in patients with enlarged hearts compared with patients with normal size hearts. The incidence of non-fatal reinfarctions, however, was independent of heart size at baseline.

The timolol related reduction of total cardiac death compared with placebo was $40.7 \%$ in patients with normal heart size, $47.8 \%$ in patients with borderline heart size, and $38.2 \%$ in patients with enlarged hearts at baseline (intention to treat approach). The reduction of first non-fatal reinfarctions in the timolol group compared with placebo was, respectively, $31 \cdot 7 \%, 41 \cdot 2 \%$, and $25.9 \%$.

Thus, timolol treatment appears to reduce cardiac death and non-fatal reinfarctions after myocardial infarction independent of heart size at baseline. Timolol treatment may be of special importance in patients with cardiomegaly, because of the very high incidence of cardiac mortality in this group of patients, and consequently a larger number of cardiac deaths may be prevented.

Cardiomegaly has been a contraindication to beta blocker treatment. Most of the postinfarction beta blocker studies have included patients with normal heart size. ${ }^{1-10}$ The unfavourable effect of alprenolol ${ }^{6}$ in patients over 65 years of age was attributed to the inclusion of a larger number of patients with large or failing hearts.

Very few studies have been performed to evaluate different interventions after myocardial infarction according to heart size. Leren ${ }^{11}$ showed, in 1966, that a plasma cholesterol reducing diet proved to be beneficial only in patients with normal heart size. The influence of heart size, however, on mortality and reinfarction in patients on long term treatment with a beta blocker is as yet unknown.

The aim of this study was to define the prognostic importance of heart size after myocardial infarction and to evaluate the efficacy of timolol treatment in reducing mortality and reinfarction relative to heart size, determined by $x$-ray film in two projections. The analyses were done retrospectively and based on the Norwegian timolol multicentre study. ${ }^{12}$

Accepted for publication 7 April 1983

\section{Subjects and methods}

In the double blind Norwegian timolol multicentre study, ${ }^{12} 1884$ patients were included, 939 in the placebo group and 945 in the timolol group. Organisation of the study, patient recruitment and evaluation, follow-up procedures, end point evaluation, data handling, statistical methods, and baseline characteristics of the patients have previously been described in detail. ${ }^{12}$

At the time of inclusion, that is six to 27 days (mean 10) after the onset of symptoms, measurement of heart size was obtained with $x$-ray film in two projections in the standing position and expressed in $\mathrm{ml} / \mathrm{m}^{2}$ body surface area. ${ }^{1314}$ According to previous studies, the heart size in women was defined as normal below $450 \mathrm{ml} / \mathrm{m}^{2}$, borderline between 450 and $500 \mathrm{ml} / \mathrm{m}^{2}$, and enlarged above $500 \mathrm{ml} / \mathrm{m}^{2}$. In men, heart size was defined as normal below $500 \mathrm{ml} / \mathrm{m}^{2}$, borderline between 500 and $550 \mathrm{ml} / \mathrm{m}^{2}$, and enlarged above 550 $\mathrm{ml} / \mathrm{m}^{2}$. All readings were done by independent radiologists.

At baseline 1199 patients (63.6\%) had normal heart 
size, 262 patients $(13.9 \%)$ borderline heart size, and 420 patients $(22.3 \%)$ had enlarged hearts (three not done).

\section{Results}

WITHDRAWALS

The withdrawal rate increased with increasing heart size at baseline, both in the placebo and in the timolol group. The total withdrawal rate was $22.4 \%$ (placebo $19.5 \%$, timolol $25.3 \%$ ) in patients with normal heart size, $27.9 \%$ (placebo $25.2 \%$, timolol $30.5 \%$ ) in patients with borderline heart size, and $36.2 \%$ (placebo $32.9 \%$, timolol $39.7 \%$ ) in patients with enlarged hearts.

During the study 70 patients $(7.5 \%)$ in the placebo group and 89 patients $(9.4 \%)$ in the timolol group developed symptoms of heart failure. Most of them continued in the study after treatment with digitalis and diuretics, and only 22 patients $(2.3 \%)$ in the placebo group and 35 patients $(3.7 \%)$ in the timolol group were withdrawn from the study because of heart failure.

The number of withdrawals caused by heart failure was larger in patients with cardiomegaly than in patients with normal heart size, but this difference was not significant (Table 1). Withdrawals caused by hypotension were independent of heart size at baseline. Withdrawals caused by bradycardia were more frequent in patients with borderline and enlarged hearts than in patients with hearts of normal size (Table 1). These differences, however, were small and not significant.

\section{DEATHS}

The frequency distribution of mortality according to baseline heart size is given in Table 2 . The data were analysed according to the patient's original randomisation (intention to treat approach). ${ }^{15}$

Cardiac mortality in the placebo group increased with increasing heart size, and was $10 \%$ in patients with normal heart size, $17.6 \%$ in patients with borderline heart size, and $27.8 \%$ in patients with enlarged hearts at baseline (Fig. 1).

In patients with normal heart size $(n=1199)$ at baseline, there were 59 cardiac deaths in the placebo group and 36 in the timolol group, a significant reduction of $40.7 \%(p<0.05)$. The number of cardiac deaths in patients with borderline heart size $(n=262)$ was 23 in the placebo group and 12 in the timolol group, a reduction of $47.8 \%$. Because of the small number of patients, this difference did not reach significance. Among 420 patients with enlarged hearts there were 60 cardiac deaths in the placebo group and 35 in the timolol group, a significant reduction of $38.2 \%$ $(p<0.05)$. The timolol related reduction in sudden cardiac death was, respectively, $29.9 \%, 50 \%$, and $43.8 \%(p<0.05)$ (Table 2).

In the timolol study ${ }^{12}$ sudden death was defined as death within the first 24 hours after start of symptoms. In the placebo group, the ratio between sudden

Table 1 Withdrawals according to heart size

\begin{tabular}{|c|c|c|c|c|c|c|c|c|}
\hline & \multicolumn{6}{|l|}{ Heart size } & \multirow{2}{*}{\multicolumn{2}{|c|}{$A \boldsymbol{l l}$}} \\
\hline & \multicolumn{2}{|l|}{ Normal } & \multicolumn{2}{|l|}{ Borderline } & \multicolumn{2}{|c|}{ Def. enlarged } & & \\
\hline & Placebo & Timolol & Placebo & Timolol & Placebo & Timolol & Placebo & Timolol \\
\hline $\begin{array}{l}\text { Cardiac failure/pulmonary oedema } \\
\text { Hypotension, systolic (BP }<100 \mathrm{mmHg}) \\
\text { Bradycardia, heart rate }(<40 / \mathrm{min})\end{array}$ & $\begin{array}{l}(n=591) \\
11(1 \cdot 9) \\
8(1.4) \\
1(0.2)\end{array}$ & $\begin{array}{l}(\mathrm{n}=608) \\
16(2 \cdot 6) \\
16(2 \cdot 6) \\
17(2 \cdot 8)\end{array}$ & $\begin{array}{l}(n=131) \\
3(2 \cdot 3) \\
1(0 \cdot 8) \\
0^{\star \star}\end{array}$ & $\begin{array}{l}(n=131) \\
4(3 \cdot 1) \\
4(3 \cdot 1) \\
9(6 \cdot 9)\end{array}$ & $\begin{array}{l}(n=216) \\
8(3.7) \\
2(0.9) \\
1(0.5)\end{array}$ & $\begin{array}{l}(n=204) \\
15(7 \cdot 4) \\
6(2 \cdot 9) \\
11(5 \cdot 4)\end{array}$ & $\begin{array}{l}(n=939) \\
22(2 \cdot 3) \\
11(1 \cdot 2)^{\star} \\
2(0 \cdot 2)^{\star \star \star}\end{array}$ & $\begin{array}{l}(n=945) \\
35(3 \cdot 7) \\
26(2 \cdot 8) \\
37(3.9)\end{array}$ \\
\hline
\end{tabular}

The numbers in parentheses represent percentages.

${ }^{\star} \mathrm{p}<0.005 ;{ }^{\star \star} \mathrm{p}<0.01 ;{ }^{\star \star \star} \mathrm{p}<0.001$.

Table 2 Distribution of mortality and first non-fatal reinfarction according to baseline heart size (intention to treat approach)

\begin{tabular}{|c|c|c|c|c|c|c|c|c|}
\hline & \multicolumn{6}{|l|}{ Hean sise } & \multirow{2}{*}{\multicolumn{2}{|c|}{$A \boldsymbol{l l}$}} \\
\hline & \multicolumn{2}{|l|}{ Normal } & \multicolumn{2}{|l|}{ Borderline } & \multicolumn{2}{|c|}{ Def. enlarged } & & \\
\hline & Placebo & Timolol & Placebo & Timolol & Placebo & Timolol & Placebo & Timolol \\
\hline $\begin{array}{l}\text { Sudden death } \\
\text { Other cardiac death } \\
\text { Total cardiac death } \\
\text { Other death } \\
\text { Total death } \\
\text { First non-fatal reinfarction }\end{array}$ & $\begin{array}{l}(n=591) \\
43(7.3) \\
16(2.7)^{\star} \\
59(10.0)^{\star} \\
4(0.7) \\
63(10.7)^{\star} \\
84(14.2)^{\star}\end{array}$ & $\begin{array}{c}(n=608) \\
31(5.1) \\
5(0.8) \\
36(5.9) \\
5(0.8) \\
41(6.7) \\
59(9.7)\end{array}$ & $\begin{array}{c}(n=131) \\
18(13 \cdot 7) \\
5(3 \cdot 8) \\
23(17 \cdot 6) \\
3(2 \cdot 3) \\
26(19.8) \\
17(13 \cdot 0)\end{array}$ & $\begin{array}{c}(n=131) \\
9(6.9) \\
3(2 \cdot 3) \\
12(9.2) \\
5(3.8) \\
17(13.0) \\
10(7.6)\end{array}$ & $\begin{array}{l}(n=216) \\
49(22.7)^{\star} \\
11(5.1) \\
60(27.8)^{\star} \\
3(1.4) \\
63(29.2) \star \\
30(13.9)\end{array}$ & $\begin{array}{c}(n=204) \\
26(12 \cdot 7) \\
9(4 \cdot 4) \\
35(17 \cdot 2) \\
5(2 \cdot 5) \\
40(19.6) \\
21(10.3)\end{array}$ & $\begin{array}{l}(n=939) \\
110(11 \cdot 7)^{\star \star \star} \\
32(3 \cdot 4)^{\star} \\
142(15 \cdot 1)^{\star \star \star} \\
10(1 \cdot 1) \\
152(16 \cdot 2)^{\star \star \star} \\
131(14 \cdot 0)^{\star \star}\end{array}$ & $\begin{array}{l}(n=945) \\
66(7.0) \\
17(1.8) \\
83(8.8) \\
15(1.6) \\
98(10.4) \\
90(9.5)\end{array}$ \\
\hline
\end{tabular}

The numbers in parentheses represent percentages.

${ }^{\star} \mathrm{p}<0.05 ;{ }^{\star \star} \mathrm{p}<0.01 ;{ }^{\star \star \star} \mathrm{p}<0.001$. 


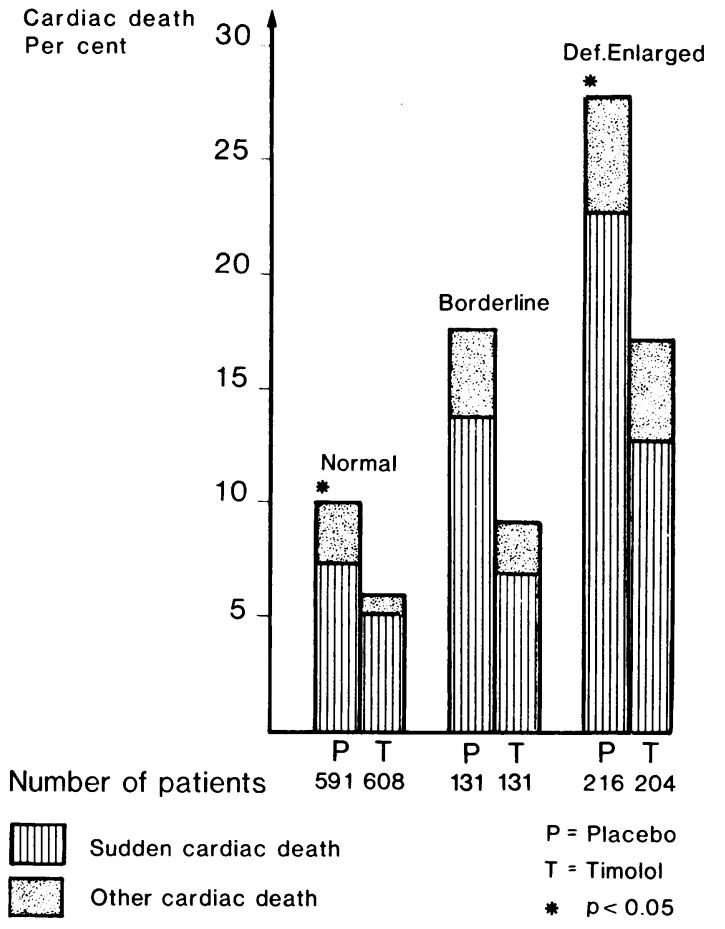

Fig. 1 Cardiac mortality according to baseline heart size.

Timolol treatment is compared with placebo.

death and other cardiac death increased with increasing heart size, suggesting that sudden (arrhythmic) death occurs relatively more frequently than other cardiac (reinfarction) death in patients with cardiomegaly as opposed to what is observed in patients with normal heart size. Compared with placebo, the ratio between sudden and other cardiac death was higher on timolol treatment, 2.7 and 6.2 , respectively, in patients with normal heart size, indicating that in this group of patients timolol treatment was related to a larger reduction in other cardiac death (mostly fatal reinfarction) than in sudden cardiac death. In patients with borderline heart size there was no difference in

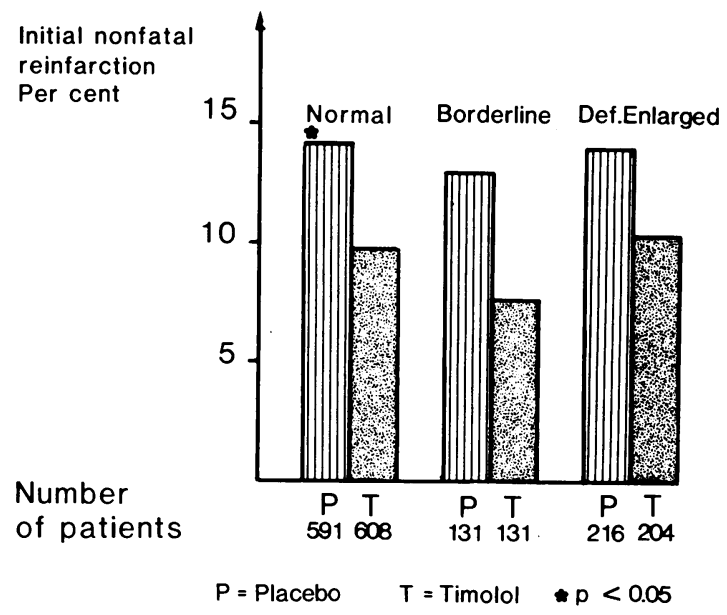

Fig. 2 First non-fatal reinfarction according to baseline heart size. Timolol treatment is compared with placebo.

the sudden death/other cardiac death ratio between the two treatment groups (placebo 3.6, timolol 3.0). In patients with enlarged hearts the ratio was 4.5 in the placebo group and 2.9 in the timolol group. Thus, in patients with cardiomegaly timolol treatment was related to a proportionally larger reduction in sudden cardiac death than in other cardiac death.

When the data were analysed according to treatment (deaths on treatment or within 28 days after withdrawal, that is using the protocol approach) ${ }^{15}$ (Table 3) the results were similar when compared with the intention to treat approach (Table 2).

\section{REINFARCTIONS}

In contrast to cardiac death, the incidence of non-fatal reinfarctions in patients in the placebo group was independent of heart size at baseline: $14.2 \%$ in patients with normal heart size, $13 \%$ in patients with borderline heart size, and $13.9 \%$ in patients with enlarged hearts.

The timolol related reduction in first non-fatal reinfarction compared with placebo was also independent

Table 3 Distribution of mortality and first non-fatal reinfarction according to baseline heart size (using protocol approach)

\begin{tabular}{|c|c|c|c|c|c|c|c|c|}
\hline & \multicolumn{6}{|l|}{ Heart size } & \multirow{2}{*}{\multicolumn{2}{|c|}{$A l l$}} \\
\hline & \multicolumn{2}{|l|}{ Normal } & \multicolumn{2}{|l|}{ Borderline } & \multicolumn{2}{|c|}{ Def. enlarged } & & \\
\hline & Placebo & Timolol & Placebo & Timolol & Placebo & Timolol & Placebo & Timolol \\
\hline $\begin{array}{l}\text { Sudden death } \\
\text { Other cardiac death } \\
\text { Total cardiac death } \\
\text { Other death } \\
\text { Total death } \\
\text { First non-fatal reinfarction }\end{array}$ & $\begin{array}{l}(n=591) \\
36(6.1) \\
9(1.5) \\
45(7.6)^{\star} \\
1(0 \cdot 2) \\
46(7.8)^{\star} \\
79(13 \cdot 4)^{\star}\end{array}$ & $\begin{array}{l}(n=608) \\
23(3.8) \\
3(0.5) \\
26(4.3) \\
3(0.5) \\
29(48) \\
53(8.7)\end{array}$ & $\begin{array}{l}(\mathrm{n}=131) \\
16(12.2)^{\star} \\
2(1.5) \\
18(13.7)^{\star} \\
1(0.8) \\
19(14.5) \\
16(12.2)\end{array}$ & $\begin{array}{l}(n=131) \\
4(3.1) \\
2(1.5) \\
6(4.6) \\
3(2.3) \\
9(6.9) \\
9(6.9)\end{array}$ & $\begin{array}{l}(n=216) \\
43(19.9) \star \\
7(3.2) \\
50(23.1)^{\star} \\
2(0.9) \\
52(24.1)^{\star} \\
30(13.9)\end{array}$ & $\begin{array}{l}(\mathrm{n}=204) \\
20(9.8) \\
6(2.9) \\
26(12.7) \\
3(1.5) \\
29(14.2) \\
18(8.8)\end{array}$ & $\begin{array}{l}(\mathrm{n}=939) \\
95(10 \cdot 1)^{\star \star \star} \\
18(1 \cdot 9) \\
113(12 \cdot 0)^{\star \star \star} \\
4(0.4) \\
117(12 \cdot 5)^{\star \star \star} \\
125(13 \cdot 3)^{\star \star}\end{array}$ & $\begin{aligned} &(n=945) \\
& \star 47(5.0) \\
& 11(1.2) \\
& \star 58(6.1) \\
& 9(1.0) \\
& \star 67(7.1) \\
& 80(8.5)\end{aligned}$ \\
\hline
\end{tabular}

The numbers in parentheses represent percentages.

${ }^{\star} p<0.05 ; \star{ }^{\star} \mathrm{p}<0.01 ; \star \star \mathrm{p}<0.001$. 
of heart size at baseline. In 1199 patients with normal heart size there were 84 first non-fatal reinfarctions in the placebo group and 59 in the timolol group, a significant reduction of $31.7 \%(p<0.05)$. The number of first non-fatal reinfarctions among 242 patients with borderline heart size was 17 in the placebo group and 10 in the timolol group, a reduction of $41.2 \%$. In the group of 420 patients with enlarged hearts there were 30 first non-fatal reinfarctions in the placebo group and 21 in the timolol group, a reduction of 25.9\% (Table 2 and Fig. 2).

The results were similar when the data were analysed according to treatment (using the protocol approach) (Table 3).

\section{Discussion}

Previous studies have shown that patients with enlarged hearts have a higher mortality after myocardial infarction than patients with normal size hearts. ${ }^{16-18}$ In the present study we show that mortality increased proportionately to the increase in heart size at baseline and was almost three times greater in patients with enlarged hearts when compared with patients with normal size hearts (Fig. 1). The incidence of non-fatal reinfarction, however, was independent of heart size at baseline (Fig. 2).

Timolol treatment in postinfarction patients is related to a significant reduction in both mortality and reinfarction as compared with placebo. ${ }^{12}$ It is of importance to identify subgroups of patients who may particularly benefit from timolol treatment or alternatively be placed at greater risk. Beta blockers reduce cardiac contractility and heart rate, and pump function in enlarged hearts may be particularly sensitive to beta blocker treatment. It is therefore important that timolol treatment is related to a reduction in cardiac mortality and non-fatal reinfarction, independent of heart size at baseline (Tables 2 and 3, Fig. 1 and 2).

Patients with severe heart failure were excluded from the timolol study; 420 patients with cardiomegaly, however, were included. The risk of giving a beta blocking agent to patients with cardiomegaly may be to increase left ventricular filling pressure, and possibly myocardial tissue pressure, which might impede regional perfusion of the myocardium. Hypothetically this may cause increased frequency of reinfarction and ischaemic heart failure. This hypothesis was not confirmed by the present study.

The cause of death after myocardial infarction may be different in patients with normal size hearts and in patients with cardiomegaly. Patients with normal hearts after myocardial infarction may have limited necrosis of the myocardium and are probably less likely to succumb from arrhythmia than from a large reinfarction. In this group of patients timolol treat- ment was related to a larger reduction in other cardiac death (mostly fatal reinfarctions) than in sudden death. This timolol related reduction in fatal reinfarction may be explained by a reduction in myocardial ischaemic injury. Patients with postinfarction cardiomegaly have large areas of myocardial necrosis and may be in an unstable arrhythmic state making them liable to sudden death. More deaths in this group of patients were accordingly reported as sudden death. Long-term administration of timolol to these patients caused a proportionately larger reduction in sudden death than in other cardiac death. Despite the fact that the mode of death seems to be different among patients with normal and large hearts, timolol appears to confer protection in both groups. Whether this protection is metabolic and/or antiarrhythmic is as yet not defined.

In conclusion, patients with enlarged hearts and compensated heart failure on treatment with digitalis and/or diuretics can safely be treated with timolol to reduce the incidence of mortality and reinfarction after myocardial infarction. The reduction in mortality and reinfarction is independent of heart size at baseline. Timolol treatment, however, is of special importance in patients with cardiomegaly, because of the very high incidence of cardiac mortality. The reduction in cardiac death in this group of patients was larger than in patients with normal heart size. Among 100 patients, timolol treatment appeared to prevent four cardiac deaths in patients with normal heart size, contrasted to 11 cardiac deaths in patients with cardiomegaly. This suggests that patients with cardiomegaly represent a special risk group which should be carefully evaluated for timolol treatment after myocardial infarction.

\section{References}

1 Reynolds JL, Whitlock RML. Effects of a betaadrenergic receptor blocker in myocardial infarction treated for one year from onset. Br Heart $\mathcal{J}$ 1972; 34: 252-9.

2 Barber JM, Boyle DMcC, Chaturvedi NC, Singh N, Walsh MJ. Practolol in acute myocardial infarction. Acta Med Scand [Suppl] 1976; 587: 213-9.

3 Baber NS, Wainwright Evans D, Howitt G, et al. Multicentre postinfarction trial of propranolol in 49 hospitals in the United Kingdom, Italy, and Yugoslavia. Br Heart f 1980: 44:96-100.

4 Wilcox RG, Roland JM, Banks DC, Hampton JR, Mitchell JRA. Randomised trial comparing propranolol with atenolol in immediate treatment of suspected myocardial infarction. $\mathrm{Br}$ Med $\mathcal{F}$ 1980; 280: 885-8.

5 Wilhelmsson C, Vedin JA, Wilhelmsen L, Tibblin G, Werkö $L$. Reduction of sudden deaths after myocardial infarction by treatment with alprenolol: preliminary results. Lancet 1974; ii: 1157-60.

6 Andersen MP, Bechsgaard P, Frederiksen J, et al. Effect 
of alprenolol on mortality among patients with definite or suspected acute myocardial infarction: preliminary results. Lancet 1979; ii: 865-8.

7 Multicentre International Study. Improvement in prognosis of myocardial infarction by longterm betaadrenoreceptor blockade using practolol: a multicentre international study. $\mathrm{Br}$ Med $\mathcal{F}$ 1975; iii: 735-40.

8 Hjalmarson $\AA$, Elmfeldt D, Herlitz J, et al. Effect on mortality of metoprolol in acute myocardial infarction. Lancet 1981; ii: 823-7.

9 Betablocker Heart Attack Trial Research Group. A randomized trial of propranolol in patients with acute myocardial infarction. $\mathcal{F A M A}$ 1982; 247: 1707-14.

10 Hansteen V, Møinichen E, Lorentsen E, et al. One year's treatment with propranolol after myocardial infarction: preliminary report of Norwegian multicentre trial. $\mathrm{Br}$ Med f 1982; 284: 155-60.

11 Leren P. The effect of plasma cholesterol lowering diet in male survivors of myocardial infarction. Oslo: Scandinavian University Books, 1966: 68-70.

12 The Norwegian Multicenter Study Group. Timololinduced reduction in mortality and reinfarction in patients surviving acute myocardial infarction. $N$ Engl f Med 1981; 304: 801-7.
13 Amundsen $P$. The diagnostic value of conventional radiological examination of the heart in adults. Acta Radiologica 1959; 181 (suppl).

14 Jonsell S. A method for the determination of the heart size by teleroentgenography (a heart volume index). Acta Radiologica 1939; 20: 325-40.

15 Hampton JR. The use of betablockers for the reduction of mortality after myocardial infarction. Eur Heart $\mathcal{F}$ 1981; 2: 259-68.

16 Vedin A, Wilhelmsen L, Wedel H, et al. Prediction of cardiovascular deaths and nonfatal reinfarctions after myocardial infarction. Acta Med Scand 1977; 201: 309 16.

17 Norris RM, Mercer CI. Long term prognosis following treatment in a coronary care unit. Aust NZ F Med 1973; 1: 31-7.

18 Norris RM, Caughey DE, Deeming LW, Mercer CJ, Scott PJ. Coronary prognostic index for predicting survival after recovery from acute myocardial infarction. Lancet 1970; ii: 485-8.

Requests for reprints to Dr Torstein Gundersen, Medical Department, Cardiology Division, Central Hospital in Rogaland, 4000 Stavanger, Norway. 